\title{
La construcción de la identidad del MERCOSUR ${ }^{1}$
}

\author{
MERCOSUR's identity construction
}

\author{
Hugo Mendoza Martinez²
}

Resumen: La llamada civilización latinoamericana, híbrido entre el mundo occidental y la población americana autóctona, está ligada a procesos de larga duración en el tiempo, en los que las ideas y doctrinas van modelando la identidad colectiva. El factor cultural, como actor internacional, talla los fenómenos de integración y desintegración territorial, como es el caso de estudio: el plan confederal Francia-Artigas y su dramática gesticulación terminal plasmada en las relaciones entre Paraguay y Corrientes, en la segunda mitad del siglo XIX, hasta toparse con la versión nominalista del Tratado del Mercosur, inconciliable con las idiosincrasias regionales.

Palabras claves: civilización, cultura, identidad, integración, Mercosur

Abstract: The Latin American civilization, a hybrid between the Western world and the indigenous American population, is linked to long-term processes in which ideas and doctrines shape collective identity. The cultural factor, as an international actor, marks both the territory's intergration and disintegration phenomena, as in this case study: from the FranciaArtigas confederal plan and its dramatic terminal gesticulation embodied in the relations between Paraguay and Corrientes during the seconf half of 19th century, to the nominalist version of the Treaty of Mercosur, which is irreconcilable with regional idiosyncrasies.

Keywords: civilization, culture, identity, integration, Mercosur

Doi: https://doi.org/10.24215/23142766e074

${ }^{1}$ Recibido el 08/10/2019. Aceptado el 27/11/2019.

2 Licenciado en Historia de la Universidad Nacional de Asunción (UNA), Paraguay, Postgrado en Formación Docente Universitaria; de Reforma del Estado; de Política y Estrategia Nacional, Doctorando en Historia, Magister en Planificación y Conducción Estratégica Nacional, Magister en Historia Medieval de Castilla y León por la Universidad de Valladolid (España), Coordinador de la carrera de Historia de la UNA. Email: mendozah33@hotmail.com 


\section{Globalización - integración, cultura y civilización}

En el abordaje de la trama cultural, franceses, británicos y norteamericanos utilizan el término civilización para aludir al cúmulo de componentes espirituales que conserva una sociedad, nacional o internacional, mientras que el término cultura lo aplican especialmente a los aspectos espirituales que identifican el temperamento de los individuos, de ahí que cuando se analizan los fenómenos colectivos se utilice el primero de ambos términos. Como resultado, para los expertos de esos países las ideas de civilización y cultura hacen referencia siempre a la dimensión inmaterial que existe y que comparten los seres humanos (ideas, valores, creencias, lenguas, religiones, etc.).

Por su parte, Maurice Duverger apoya la tesis de que los conjuntos culturales se van articulando históricamente de forma diversificada, aunque siguiendo pautas o pasando por estadios análogos que permiten contemplarlos como partes de congregaciones más amplias a las que intitula "civilizaciones". Por ende, las civilizaciones son realidades sociales surgidas históricamente como resultado de la aglutinación de los conjuntos culturales o por evolución de alguno de ellos, básicamente a partir de los elementos reiterados que existen en sus creencias, instituciones, técnicas, condiciones geográficas y demográficas (Calduch, 2003: 3-5).

La civilización, como la fija Samuel Huntignton, pasa a ser concebida meramente como "familia cultural", despojada de su sentido normativo. En efecto, ya no tenemos muchas culturas sino sólo una civilización. La civilización, dice este autor, "es el agrupamiento cultural humano más elevado y el grado más amplio de identidad cultural que tienen las personas, si dejamos aparte lo que distingue a los seres humanos de otras especies" (Lamo de Espinosa, 2018: 5).

El factor cultural, desde la perspectiva de cada actor internacional, constituye un elemento de semejanza o diferenciación entre los órdenes internos y los hábitos exteriores de los actores internacionales, ya que delimita el contexto de valores, ideas, conocimientos y formas de vida que incidirán netamente en la toma de decisiones y en las acciones que realicen como tales, así como el grado de apoyo o de resistencia social que tales determinaciones y actuaciones ocasionarán.

En cuanto a las relaciones internacionales de índole cultural, su tratamiento desde una perspectiva holista de las sociedad internacional (nivel macrointernacional), aborda primordialmente las relaciones interculturales, o sea las que se generan y desarrollan por parte de las propias culturas, en cuanto actores internacionales, o por otras figuras cuya naturaleza es ciertamente cultural y cuyos efectos inciden directamente en el soporte civilizatorio común (Calduch, 2003: 21-13).

El concepto de identidad no puede separarse de la significación de cultura, ya que las identidades sólo pueden construirse a partir de las diferentes culturas y subculturas a las que se pertenece o en las que se participa.

Tratándose de actores sociales, la identidad es la construcción de sentido, atendiendo a uno o varios atributos culturales y priorizándolos por sobre el resto de atributos, que es construida por el individuo y representa su autodefinición (Vera \& Valenzuela, 2012: 273). 


\section{América Latina}

América Latina es una "familia cultural" diferente de la occidental y, por lo tanto, de la filiación de América del Norte. Esto lleva a la pregunta: ¿es América Latina otra civilización? ¿Pertenece a otra familia cultural distinta de la familia occidental?

Huntington identificaba expresamente ocho civilizaciones, a saber: la occidental, la islámica, la sínica, la hindú, la ortodoxa, la budista, la japonesa y, finalmente, la latinoamericana, además de una posible novena, la africana. Para él, era pues evidente que América Latina no forma parte de la civilización occidental.

¿Cuáles son las características de la civilización occidental? Huntington menciona las siguientes: el legado de los clásicos, la pluralidad de lenguas, la separación entre autoridad espiritual y temporal, el Estado de Derecho, el pluralismo social, el individualismo, la representación política y, sobre todo, el cristianismo occidental, es decir, el catolicismo y el protestantismo.

La civilización latinoamericana -aunque muy vinculada con Occidente-, por el contrario, "incorpora elementos de antiguas civilizaciones indígenas" y es un híbrido entre el mundo occidental y la población americana autóctona, y tiene una cultura popular y despótica que Europa tuvo también pero en un grado menor, y que América del Norte nunca tuvo (Lamo de Espinosa, 2018: 6-9).

Los procesos independentistas de inicios del siglo XIX se sustentaron de forma decidida en una fuerte construcción nacional y en el culto a los símbolos patrios (bandera, himnos, próceres, etc.), lo cual acentuó las diferencias y singularidades que exteriorizaban cada uno de los nuevos Estados que se erigieron. La reafirmación nacional, de esta forma, fue avivada en detrimento de proyectos de unidad y de confianza recíproca entre los vecinos (Caballero, 2014: 846).

Cabe simplemente evocar algunos pasajes de la Carta de Jamaica: "Yo deseo más que otro alguno ver formarse en América la más grande nación del mundo, menos por su extensión y riqueza que por su libertad y gloria" (Kingston, 1815).

La convocatoria para el Congreso la realizó Bolívar desde Lima, en diciembre de 1824 y en ella se especifican las funciones que debía cumplir este: servir de consejo para los grandes conflictos, de punto de contacto con los peligros comunes, de intérprete de los tratados públicos ante posibles dificultades y de conciliación de las diferencias. Bolívar estaba pensando una reunión que dejara en funciones un organismo permanente, una liga de naciones hispanoamericanas independientes, a la que denominó "Liga Anfictiónica".

El panamericanismo tuvo su origen en la doctrina Monroe, la que proviene de la proclamación del presidente James Monroe, ante el Congreso de los Estados Unidos en 1823, por la que el continente americano no sería lugar de colonización de las grandes potencias europeas nucleadas en la Santa Alianza. Su visión quedó condensada en la expresión: "América para los americanos", cuya ambigüedad no tardó en ponerse de manifiesto con las ocupaciones y usurpaciones sufridas por México, Cuba, Puerto Rico y Panamá durante el siglo XIX (Arpini, 2013: 155).

Empero “América Latina” es una etiqueta creada por Napoleón III en 1860 como un proyecto político francés antiamericano sobre México. Francia debía participar con una política exterior panlatina como una categoría niveladora frente a los países anglosajones. Pero algunos de los argumentos anticipados por aquel entonces por Michel Chevalier, el portavoz de las ambiciones de Napoleón, tienen cierto sentido (Lamo de Espinosa, 2018: 14). 
En la "Introducción", Chevalier traza un plan general de la civilización, cuyo fin es la unidad de la humanidad y la explotación industrial del mundo. Distingue entre germanos en cuyo seno discierne el grupo sajón y el eslavo-y latinos. Simultáneamente anuncia el rol que a estos pueblos correspondería en la consecución del "equilibro del mundo". Si hasta ese momento el papel predominante había sido de los pueblos de origen sajón, los de "cepa latina", con Francia a la cabeza, no podían quedar atrás. América es vista, por otra parte, como el puente de empalme entre Occidente y Oriente.

La ideología civilizatoria de Chevalier, en la que se encuadra el uso del término "latino" para calificar a Europa y América, evita hacer mención a las formas de vida existentes en el nuevo continente y legitima en los hechos la invasión francesa a México entre 1861 y 1867. Se evidencia de igual forma que la significación del término es fruto de una mentalidad europea moderna, agresivamente colonial, sostenida en argumentos figuradamente ilustrados que invocan al progreso de la civilización, así como a la diferencia y supremacía de las razas.

En otro orden, el panamericanismo tuvo su continuación con el llamamiento para la Conferencia Internacional Americana que se reunió en Washington entre octubre de 1889 y abril de 1890 y a la que el senador James Blaine designa como "Primera Reunión Panamericana". Desde que Blaine ocupó la Secretaría de Estado, bajo la presidencia de James A. Garfield en 1881, se adoptó una política agresiva con relación a las Repúblicas de Centro y Sur América, sostenida por una interpretación de la Doctrina Monroe, que proponía un sistema hemisférico basado en el intercambio pacífico, procedimientos de arbitraje y conferencias para tratar los problemas interamericanos en general (Arpini, 2013: 146-155).

América Latina no es una unidad ni política ni económica. Sin embargo, conforma una unidad cultural en estado líquido cenagoso (Lamo de Espinosa, 2018: 16). A través de la unión económica se intentó reavivar el esfuerzo de integración, que se dirigió hacia el desarrollo, en la década del sesenta, bajo principios proteccionistas y defensivos, propios de una economía cerrada, cuyos resultados fueron muy limitados. De esta manera, el Tratado suscrito el 18 de febrero de 1960 creó la Asociación Latinoamericana de Libre Comercio (ALALC) por medio del mecanismo económico instrumental, a la que luego le siguió y sustituyó el Tratado de Montevideo en 1980, que instituyó a la Asociación Latinoamericana de Integración (ALADI).

En los años noventa, se revalorizó la integración, presuponiendo el aprovechamiento de las bases objetivas creadas por la proximidad geográfica y las similitudes históricas, culturales y lingüísticas, e incorporando en su dinámica incluso a países muy distantes o localizados en zonas muy extensas, como la Cuenca del Pacífico (Romero, 1999: 68).

Siguiendo esta ola integracionista, el 26 de marzo de 1991 en Asunción, Paraguay, los presidentes de la Argentina, el Brasil, el Paraguay y el Uruguay firmaron el Tratado de Asunción. El objetivo del Tratado fue la creación de un mercado común (Benegas; 1994: 27) como una manera de acelerar el proceso de desarrollo económico y la justicia social de sus países miembro.

La firma del tratado fue una sorpresa: no hubo discusión previa ni debates sobre el tema. El tratado fue el punto de partida de las discusiones, ya sea a favor o en contra (Benegas, 1994: 28); o sea que no hubo padres o mentores que hayan pensado con anterioridad la unión.

Subsiguientemente, saberse dentro del Mercosur supone imaginarse en qué lugar, en calidad de qué, para qué se está allí - en lugar de no estar. Toda identidad es, por definición, 
reactiva, pues nace de la confrontación dialéctica y constitutiva con lo que ella no es (Andacht, 2001: 312-317).

\section{El proyecto confederal Francia-Artigas}

El abordaje de la materia cultural integracionista implica retroceder un largo trecho en el tiempo. En primer lugar, las medidas adoptadas por los Borbones para aumentar la producción en las Misiones jesuíticas fracasaron y, además, aceleraron la fuga de su población. No llegó a formarse ninguna elite local que pudiera ejercer el poder en beneficio de los intereses de la provincia y la región del Alto Plata, donde se desarrollará la idea de la confederación.

Al Supremo Dictador del Paraguay, Doctor José Gaspar Rodríguez de Francia, le interesaba vivamente la idea de la confederación. La nación o los pueblos hispanoamericanos están constituidos por comunidades que integran el racimo de reinos del imperio español, bajo la autoridad de la corona, cada una con intereses propios y un derecho inalterable a la

libertad. Él aceptaba que se pudiera ceder parte de los derechos, cuando los otros hicieren lo mismo, con miras a una autoridad confederada libremente consentida, más nunca para la sumisión, jamás para reconocer la superioridad de Buenos Aires ni de nadie.

Fue entonces que José Gervasio Artigas resolvió recoger la bandera abandonada por el Paraguay y convertirse en el adalid de la confederación en el Río de la Plata. El plan confederal del Dr. Francia, que venía a satisfacer una y otra aspiración (preservar la unidad del virreinato y a la vez la autonomía local), fue acogido por Artigas, si no literalmente en su esencia, en las famosas Instrucciones del año 1813 a los diputados orientales a la Asamblea convocada por Buenos Aires para concertar la forma definitiva del gobierno de las Provincias Unidas (Mendoza, 2011: 75): “Artigas en su idea federal, pero también en su defensa de la autonomía local, Paraguay en su autarquía y aislamiento, no debían ser una amenaza para el desarrollo y consolidación de la vieja trenza porteño-lusitana" (Abreu, 2016: iii-iv).

En los nueve años de actuación en el escenario mayor de la primera época independiente, Artigas libró invariablemente un lucha orientada en dos direcciones: contra el enemigo externo -se llamaren españoles o portugueses- y contra el poder centralista de Buenos Aires. Emancipación y confederación serían, entonces, los dos objetivos perseguidos por Artigas con una constancia y lucidez pasmosas. Artigas se establece en su calidad de "protector", en la multiplicidad de nociones que encierra el concepto: como un guardián que protege con autoridad, y se podría decir que hasta como un "padre" que ayuda a crecer e independizarse a sus hijos (Abreu, 2016: 8-9).

La idea de la integración económica y social como un proceso de complementación en dichos planos llevado a cabo por diversas unidades políticas institucionalmente iguales y autónomas, que admite una sucesión o una yuxtaposición simultánea de grados o formas, con la finalidad de formar un espacio o bloque macroeconómico completo y desarrollado, es un concepto que trasluce la aspiración común de autarquía política y económica; es decir, que el espacio o bloque económico y social se baste a sí mismo, eliminando o atenuando la dependencia política y económica proveniente del espacio exterior.

Las instrucciones orientales planteaban, de manera inequívoca, las grandes libertades básicas de comercio, de navegación, de tránsito, incidiendo sobre vitales intereses y privile- 
gios de la capital (Manzoni; 2005, 123-128). Y las condiciones no eran otras más que el respeto de "las individualidades políticas provinciales", la libre navegación de los ríos, el proteccionismo económico y la nacionalización de las rentas de la aduana (Chiaramonte, 2013: 163). Uno de los rasgos claves de la definición de identidad sería la constancia a la palabra dada. El otro, el feroz y sempiterno rival, en cambio, es presentado como el que se apoya en la pura fuerza bruta (Andacht; 2001: 325).

Las provincias del litoral continuaron abrigando, en algún momento, intenciones de convertirse en un Estado independiente junto a la Banda Oriental y, posiblemente, también con el concurso de Río Grande del Sur (Chiaramonte, 2013: 162).

\section{La división de los pueblos del Plata: unitarios y federales}

El general Bartolomé Mitre, un diestro manipulador de la historia hacia sus metas políticas, señaló las diferencias al estudiar la forma como se realizó la conquista de América. Observó que los conquistadores del Río de la Plata ocuparon una región poblada por tribus sin cohesión, sin metales preciosos, ni recursos para la vida civilizada. Los naturales de índole mansa se plegaron al yugo español; los belicosos, después de derrotados, cedieron el terreno y se retiraron a territorios lejanos.

La vastísima región, que luego mereció ser llamada "Provincia gigante de Indias", antes de llegar los castellanos, estuvo poblada por numerosas parcialidades indígenas, pertenecientes a diversas razas, pero la que contaba con mayor número era la guaraní.

Esta, muy numerosa, se hallaba esparcida desde las costas atlánticas del Brasil y, después de cubrir toda la parte central del Continente, se extendía hasta el Amazonas. Pero si existía una unidad racial, no había unidad política. Al contrario, las naciones indígenas estaba fraccionadas en parcialidades antagónicas, que muchas veces se trababan en luchas (Lafuente Machain, 2005: 300-303).

La revolución de mayo de 1810 se basó en dos argumentos jurídicos: las doctrinas de retroversión y de la subrogación. La doctrina de la retroversión afirmaba que el poder residía en la Corona, porque así le fue otorgado por Dios, pero al verse arrebatada la Corona de su legítimo titular, Fernando VII, y quedar acéfala la Monarquía, la soberanía popular se retrotraía al pueblo, quien retomaba sus derechos soberanos y podía, por tanto, darse las autoridades que juzgase más convenientes (Abreu, 2016: 11). Según ese pacto, el único soberano es el rey, cuya falta hace que la soberanía se retrovierta al pueblo americano (Chiaramonte, 2013: 196).

Por la doctrina de la subrogación, complementaria de la anterior, la Junta de Mayo en Buenos Aires sustituirá al virrey, subrogándose en todos los poderes de este y en todas sus atribuciones, incluso dentro de los límites territoriales del virreinato. Este concepto es el que pretendió justificar el poder central que la Junta de Buenos Aires comenzó a ejercer sobre todas las demás provincias y explica, entre otras cosas, la primera expedición al Alto Perú. Para responder a la objeción evidente de por qué la Junta de Buenos Aires se "subrogaba" en los derechos de todo el virreinato (y no solo en los del pueblo de Buenos Aires), haciendo caso omiso a los derechos retrotraídos de los demás pueblos, la Junta porteña tuvo que dar un paso más e inventó la doctrina de la "hermana mayor", autoproclamándose tuteladora de los intereses generales (Abreu, 2016: 11). 
El virreinato platense, desde el punto de vista institucional, constituyó no solamente una unidad u ordenamiento administrativo, sino también una organización política que la revolución bonaerense del 25 de mayo de 1810 quebró definitivamente de hecho y de derecho, no siendo suficiente para negarle esta característica la diversidad de regionalismos que, aunque cierta, nunca comprometió la unidad general del conjunto (Manzoni, 2005: 126).

La formación de un estado confederal platense no basaba su legitimidad en el supuesto de la nacionalidad -por lo demás inexistente- sino en relaciones contractuales propias del derecho natural. Además, por entonces tampoco existía el concepto mismo de nacionalidad, en el sentido propio del principio de nacionalidades, aparecido posteriormente.

Las sociedades rioplatenses de la época poseían una confrontación basada en normas constitucionales de antigua data, las que se correspondían con formas de conducta social y de acción política congruentes con aquellas, y las nuevas reformas de carácter constitucional que se adoptaron luego de 1820 , pese a que tuvieron no pocos defensores, carecieron del arraigo necesario para imponerse a largo plazo.

Paralelamente, como en otras regiones del continente $-y$ tal como había ocurrido también en las ex colonias angloamericanas-, estalló el conflicto entre los partidarios de un Estado unitario y los que buscaban otra forma de vínculo, la confederación, que permitiera a las provincias preservar su calidad estatal soberana, dado que la confederación no es un Estado sino, como lo había explicado Montesquieu, una sociedad de estados soberanos independientes (Chiaramonte, 2013: 89, 228 y 245).

Fracasado el proyecto confederal artiguista, el desmembramiento del viejo virreinato solo será cuestión de tiempo. Las Provincias Unidas se sumergirán en una guerra civil que continuará por décadas, Paraguay profundizará su aislamiento y el Uruguay independiente sobrevivirá a partir de la Convención Preliminar de Paz entre sus dos grandes vecinos, siendo objeto, sujeto y escenario del conflicto entre "federales" y "unitarios", de la voluntad expansiva lusitana y de la necesidad de Buenos Aires de unificar Argentina bajo la conducción de sus intereses portuarios (Abreu, 2016: 37).

La nacionalidad argentina no existía en la primera mitad del siglo XIX, pues recién se comienza a hacer realidad con la guerra del Paraguay. Por lo tanto, carecía de valor acusar a Corrientes de haber atentado contra el principio de unión entonces inexistente (Whigham, 2009: 112-113).

En primer lugar, se debe tomar en cuenta la cercanía de Corrientes con Asunción que emerge desde la etapa fundacional: Corrientes fue fundada por asunceños. Desde un principio, los vínculos comerciales, sociales y políticos de Corrientes se generaron en alianzas o enfrentamientos con la capital paraguaya. Esta situación también se hará presente tras los movimientos revolucionarios de 1810 en adelante por constituir regiones del Alto Plata ubicadas en la periferia de las luchas entre unitarios y federales.

Los integrantes del Cabildo correntino mantendrán una política pendular entre Asunción y Buenos Aires (Ramírez, 2018: 73), el cual había quedado en manos de una elite de comerciantes prósperos y hacendados que trataron de mantener a flote el comercio correntino. Aquella elite tuvo cierto éxito entre 1820 y 1830 . Sin embargo, solo alcanzó un progreso muy limitado en las tres cuestiones prioritarias: la protección de las industrias artesanales locales, la prohibición de ingreso ilimitado de productos extranjeros en los mercados provinciales y la apertura permanente de los ríos a los buques comerciales extranjeros (Whigham, 2009: 305). 
La provincia de Corrientes, que junto a Santa Fe había sido una de las más fuertes sostenedoras del criterio de que la nación no existiría hasta tanto no se tuviese una constitución "federal", pasó a sostener, luego del fracaso del Congreso de 1824-1827 y de la Convención de 1828, la ya existencia de una nación argentina y a urgir la constitución que le faltaba. Buenos Aires, por su parte, que había sido principal sede de la tendencia unitaria, a partir de los gobiernos de Rosas pasó a ser campeona de la confederación y a oponerse a la organización constitucional.

La falta de una adecuada comprensión de la cuestión reside aun hoy en no advertir que lo que se ha llamado federalismo no era en realidad confederacionismo, mientras que la solución de 1853, preparada por el Acuerdo de San Nicolás, fue la de un Estado federal que anuló la soberanía absoluta de las provincias (Chiaramonte, 2013: 245).

El sistema institucional federal-formal que se pretendía implantar requería de la actuación de factores infraestructurales dinámicos y constructivos -como los que libera un proceso de integración económica-capaces de coadyuvar a la constitución real de la unidad política, cultural e institucional del sistema (Manzoni, 2005: 130-131).

Cuando los correntinos necesitaron apoyo a su política de oposición al gobierno de Juan Manuel de Rosas, numerosos vínculos políticos y económicos entrelazaron a correntinos y paraguayos. La situación fronteriza y geoestratégica de Corrientes enriquecerá sobremanera la forma en que los correntinos se relacionaran con Buenos Aires, Río de Janeiro y Asunción (Ramírez, 2018: 69, 73 y 74).

Las relaciones entre Paraguay y Corrientes se formalizan en julio de 1841, cuando se firmaron en Asunción los tratados sobre comercio y límites que asignaron al Paraguay los territorios del norte del río Aguapey y concedían el control de los establecimientos del Apipé y el río Uruguay a Corrientes. Los vados del río de Itatí, Yababirí e Itapúa, en el Alto Paraná, fueron declarados abiertos al comercio correntino, como lo fue Pilar en el Paraguay. En reconocimiento a la unidad cultural y lingüística de las dos partes, el tratado declaró que: "Los hijos de ambos estados serán considerados nativos de uno y otro... con libre ejercicio de sus derechos" (Whigham, 2009: 112-113).

Aquellos que prestaron colaboración a los paraguayos procedían de una cercanía política al partido federal, originado en el urquicismo (Ramírez, 2018: 69-74), que mantenía aun bolsones de la idea confederal de Francia y Artigas.

El panorama político del Plata cobró nuevo cariz en septiembre de 1861, cuando la milicia porteña venció a las tropas de la Confederación en la batalla de Pavón, en la provincia de Buenos Aires (Whigham, 2009: 151). Bartolomé Mitre y su visión unitaria y elitista sintetizada en la frase "civilización o barbarie" de Domingo Faustino Sarmiento, y el espíritu expansivo del Imperio del Brasil, marcaronn dos pilares de una bilateralidad renovada que continuará funcionando y determinando el devenir de la región platense.

El imperio brasileño no solo era un régimen esclavista, sino también una monarquía devenida en estatus imperial, con marcadas intenciones de expansión territorial. Por su parte, Buenos Aires no representaba a la totalidad de las Provincias Unidas, porque los intereses portuarios, centralistas y monopolizadores en la recaudación de la renta aduanera -ya de por sí incompatibles con los intereses y necesidades de las demás provincias- se acompañaban, además, de un pensamiento liberal, europeo, de difícil convivencia con el caudillismo que, en el ámbito hispánico, sustituyó al gobierno de la metrópoli y predominaba en las provincias del interior. 
Pero junto al liberalismo porteño y el Imperio esclavista y expansivo de Brasil, existe un tercer actor a considerar. El valor geopolítico que tenía la Cuenca del Plata no era algo a lo que Europa estuviera ajena y, mucho menos, Gran Bretaña, que desde Trafalgar se había transformado en dueña de los mares e imponía su concepto de "pax británica", es decir, moneda segura y libre comercio, la antítesis del monopolio secular español (Abreu, 2016: 39).

¿Se trataría de un objetivo de "ensanche" de las nacionalidades americanas postulado por Bartolomé Mitre en 1862, cuando recién asumido el gobierno, propuso en un editorial de La Nación la "anexión reciproca de las repúblicas limítrofes"?

La vieja vocación expansiva brasileña parece animar ahora también al gobierno de Buenos Aires y las dificultades para sellar la alianza tan empeñosamente buscada por el Brasil pueden haber obedecido a las dificultades por aceptar desmesuradas pretensiones argentinas. El nudo de la discordia, que casi llevará a la ruptura a los aliados al finalizar la guerra, ya está puesto en los orígenes de su arreglo.

La alianza con Mitre consolidará la muerte de todo sueño federal y la unificación de Argentina en una única y gran republica controlada por la siempre pretenciosa capital. En otras palabras, el protocolo quedó en proyecto, porque todavía no estaba fijado el "precio" que la Argentina cobraría por aliarse con Brasil, o los términos del reparto; pero los principales términos de la alianza estaban fijados desde octubre de 1864.

El enemigo eran los porteños, Mitre, los "macacos brasileños", el liberalismo. Por esta razón, cuando Mitre llama a todas las provincias a movilizarse contra el gobierno de Francisco Solano López, y Urquiza repite el llamamiento al pueblo entrerriano, ordenando movilizar a todas las fuerzas provinciales en el campamento de Calá, termina de quebrar el último limite moral admisible para muchos de sus seguidores de siempre.

Pero la oposición en el interior de la Argentina hará que batallones enteros se nieguen a luchar contra los hermanos paraguayos. Las palabras que el general Ricardo López Jordán le dirige a Urquiza, cuando éste ordena la movilización de las caballerías entrerrianas para ir en apoyo de Brasil y contra Paraguay, sintetizan acabadamente el sentimiento de indignación que provoca la actitud del caudillo (Abreu, 2016: 323-348): "Usted nos Ilama a combatir al Paraguay, le contestó - Nunca, General: ese pueblo es nuestro amigo. Llámenos a pelear a porteños y brasileños. Estamos prontos, esos son nuestros enemigos".

A la orden de movilización de Urquiza se presentaron 8.000 voluntarios, la mayor parte de ellos entrerrianos convencidos de que iban a unirse a los paraguayos contra los brasileños. Fueron reunidos en cinco columnas y comenzaron a marchar hacia el norte, pero al llegar al pueblo de Basualdo se enteraron de qué lado iban a pelear y, simplemente, se fueron para sus casas. El "Desbande de Basualdo", ocurrido en julio de 1865, no fue reprimido por el gobierno, pero la siguiente "Sublevación de Toledo", de noviembre, fue duramente reprimida con el auxilio de tropas brasileñas y floristas. Al final, la violencia será la única forma eficaz de reclutar "voluntarios" para ir a la guerra. Urquiza mandará fusilar a varios de los sublevados, pero no logrará reunir un tercer contingente.

La revolución se extendió rápidamente a las provincias argentinas de San Luis, San Juan y La Rioja. Habrá montoneras en todas partes y las fuerzas nacionales tardaron más de un año en vencerlas, por lo que Mitre recién pudo regresar a la contienda en Paraguay hacia julio de 1867. Pero la guerra contra Paraguay era tan resistida que nuevas revoluciones surgieron en Santa Fe y luego en Corrientes, mientras la guerra continuaba y los contingentes y reclutas se sublevan y escapan. Ante la magnitud del levantamiento contra el gobierno, el 
ejército nacional es retirado del frente paraguayo para combatirlo y hasta el propio general Mitre debe regresar a Argentina (Abreu, 2016: 349-351).

Corrientes había sido atacada desde varias direcciones y los correntinos eran incapaces de expresar una opinión independiente de la de Buenos Aires. Ciertamente, Nicanor Cáceres y Justo José Urquiza seguían ejerciendo cierta influencia en la provincia gobernada por autoridades títeres, y, en general, la población correntina se mantenía hostil a Mitre (Whigham, 2009: 161).

El desprestigio de Mitre hizo imposible que en 1868 pudiera hacer triunfar la candidatura de quien había sido su Ministro de Relaciones Exteriores, el ardoroso triplealiancista Rufino Elizalde, porque la impopularidad de la guerra contra el Paraguay había barrido con gran parte de la ascendencia de ambos (Dotta, 2012: 480).

Los correntinos no estaban en posición de enfrentarse a Buenos Aires, y en 1868 Mitre usó el pretexto de las disensiones internas para echar al gobernador "cacerista" Evaristo López, reemplazándolo por una persona más cercana a Buenos Aires. En octubre de 1869, Santiago Baibiene, el más decidido de los mitristas correntinos, fue nombrado gobernador. La victoria de Buenos Aires fue completa. Corrientes nunca más pudo acercarse al Paraguay en busca de alguna alianza regional en el Alto Plata; de allí en adelante, Buenos Aires y su idea de nacionalidad argentina se impusieron en esta provincia (Whigham, 2009: 161).

\section{Relación Paraguay-Corrientes en la guerra contra la Triple Alianza}

La ubicación geográfica de Corrientes hizo que ésta se transformara en una pieza estratégica clave para todo el desarrollo de la guerra que libró la Triple Alianza (Ramírez, 2018: 69-74). Se sabía que el gobierno de Mitre consideraría el paso de fuerzas paraguayas por su territorio como una violación que implicaba casus belli.

Para interponerse entre las fuerzas brasileñas y las orientales, le era ineludible al ejército paraguayo transitar por Argentina. Esta circunstancia ya había sido prevista tanto por el gobierno mitrista como por el Imperio del Brasil, quienes sabían que si el imperio cumplía su amenaza de represalias y atacaba al Uruguay, Paraguay querría atravesarse entre las fuerzas invasoras y las orientales y que, para ello, debería cruzar territorio correntino. Si Argentina negaba el tránsito, ello implicaría una violación de su soberanía y "obligaría" a su gobierno a declararle la guerra al Paraguay. La alianza con el Brasil quedaría justificada (Abreu, 2016: 322-324).

El 5 de marzo de 1865, había comenzado sus sesiones en Asunción un Congreso extraordinario llamado por el presidente López, el que, en sesión del 18 de marzo, declaraba la guerra a la Argentina (Dotta, 2012: 420).

En fecha 6 de febrero de 1865, el presidente López dirige una carta al gobernador Urquiza expresándole que:

Siendo probable que los azares de la guerra en que se halla empeñada esta República con el imperio del Brasil, me arrastren a pisar alguna parte del territorio argentino de Corrientes y deseando guardar con el Gobierno Nacional toda consideración y respeto que me deben los derechos internacionales y la seguridad de neutralidad de VE me asegura el parte del Gobierno argentino, he mandado dirigirle la nota de solicitud cuya copia hallará VE adjunta... (Abreu, 2016: 325). 
El 14 de abril de 1865 el general paraguayo Wenceslao Robles, al frente de un fuerte ejército de 14.000 infantes y 6.000 de caballería, toma sin resistencia la ciudad de Corrientes. En tanto Mitre niega el paso y Urquiza se mantiene indefinido y juega a dos puntas, López no espera más al escurridizo Urquiza y toma la resolución de forzar el paso, como había advertido en la declaración de guerra, ocultada por Mitre (Castagnino, 2010: 275-276).

Los paraguayos no fueron recibidos en la ciudad como invasores y Robles mantiene la disciplina de sus tropas, declarando a la población que la guerra era contra Mitre, "auxiliar de los brasileños". Tres conocidos correntinos de trayectoria, Victor Silverio, Teodoro Gauna y Sinforoso Cáceres, son nombrados por el consejo municipal, y aprobados por Robles, como administradores de la zona ocupada. Víctor Silvero, amigo personal de Solano López, será después de la guerra juzgado por "alta traición" y absuelto.

Silvero compartía, como muchos argentinos, la opinión de López y acepta el cargo ante la manifestación de López de que "el pueblo argentino nada debía temer, pues la guerra no era contra el pueblo sino contra sus usurpadores", quien además les da seguridades de respetar la soberanía, los bienes y derechos de los correntinos (Castagnino, 2010: 275-276).

La junta de correntinos paraguayistas lanzó un decreto en el que declaraba al Gobierno de Mitre traidor a la patria y se aliaba con el Paraguay, además de una proclama elogiosa para los paraguayos: “...cuya única misión entre nosotros es defender la independencia de las repúblicas del Plata, hostilizadas por el Emperador del Brasil, y comprometidas por la política insidiosa del Gobierno de Mitre..." (Dotta, 2012: 421).

La junta redobló esfuerzos para generar una cierta independencia de las decisiones provenientes del Gobierno de Asunción y, paralelamente, intentaron instalar la idea de un enfrentamiento con el Gobierno argentino presidido por el general Bartolomé Mitre y su alianza con Brasil.

En aquel intento, impusieron algunas disposiciones que pretendían el manejo de su propia soberanía, como la que estableció que la bandera correntina fuera la que flameara en los edificios públicos y la que debía ser portada por los batallones provinciales. Su primer acto fue entregar a la columna la bandera correntina, afirmando que "ella simbolizaba a la Patria y su misión". Esta disposición se mantuvo hasta los últimos momentos de la ocupación paraguaya.

Además, la Junta de Corrientes dispuso, para la identificación de sus soldados, un uniforme propio que se diferenciase del paraguayo y de las tropas aliadas. Las manifestaciones de esa naturaleza fueron constantes durante los meses que duró la Administración política de la Junta Gubernativa.

Las simpatías de algunos correntinos por el Paraguay en vísperas de la guerra se arraigaban fuertemente en las posturas de los antiguos enfrentamientos con Buenos Aires y las desconfianzas con el Brasil. Aquellos que decidieron colaborar con las fuerzas paraguayas en 1865 observaron que una alianza con el Paraguay podría ser la última oportunidad de enfrentamiento al proyecto de construcción del país desde Buenos Aires, tal como quedó afianzado unos años antes en la batalla de Pavón, con el triunfo porteño sobre la Confederación Argentina.

Las mayores y más expuestas simpatías de los correntinos con paraguayos fueron manifiestas en la ocupación de cargos públicos y en la formación de batallones militares. Luego de los meses de ocupación paraguaya y el retiro de ésta del territorio provincial, lo correntinos "paraguayistas" más comprometidos cruzaron el río Paraná y se trasladaron con las 
tropas del vecino país. Otros, sin embargo, quedaron en Corrientes y negaron toda participación y vinculación (Ramírez; 2018: 72-75).

La comunicación al general Francisco Isidoro Resquin sobre Uruguayana, Humaitá, 30 de octubre de 1865 dice:

quiero que recibiendo esta $\mathrm{V}$ disponga la retirada compacta de la División incluso el Comandante Bruguez...no aceptando la acción y teniéndome al corriente de sus movimientos y del enemigo, arreando toda clase de ganados y caballos que puedan en su marcha, y mandando dar recibos a sus propietarios, haciéndoles entender de que con esa operación necesaria se quita recursos al enemigo, y que ese recibo que $\mathrm{V}$ manda dar importa la obligación de pagarlos (López, 1996: 126).

Tras la guerra contra la Triple Alianza, Corrientes nunca más pudo acercarse al Paraguay en busca de alguna alianza regional en el Alto Plata y, de allí en adelante, Buenos Aires y su idea de nacionalidad argentina se impusieron por la fuerza en ese tronco periférico regional.

\section{Conclusión}

Este no es un trabajo que pueda cerrarse de manera palmaria, por su carácter abierto a la reflexión y a la polémica, que es la postura que reclama el tema tratado y el enfoque que hemos ofrecido. La conversión de las ideas en fuerzas históricas no es tan inmediata ni tan simple; normalmente se trata de procesos de larga duración en el tiempo, en los que las ideas y doctrinas van modelando la conducta, individual o colectiva.

El término civilización alude, como hemos dicho, al cúmulo de componentes espirituales que conserva una sociedad, nacional o internacional. Las ideas de civilización y cultura hacen referencia siempre a la dimensión inmaterial que existe y comparten los seres humanos.

El factor cultural, desde la perspectiva de cada actor internacional, constituye un elemento de semejanza o diferenciación entre los órdenes internos y los hábitos exteriores de los actores internacionales, ya que delimita el contexto de valores, ideas, conocimientos y formas de vida que incidirán netamente en la toma de decisiones y en las acciones que realicen como tales, así como el grado de apoyo o de resistencia social que tales determinaciones y actuaciones ocasionarán.

Los conjuntos culturales se van articulando históricamente de forma diversificada aunque siguiendo pautas o pasando por estadios análogos; son realidades sociales surgidas históricamente como resultado de la aglutinación de los conjuntos culturales o por evolución de alguno de ellos, básicamente a partir de los elementos reiterados que existen en sus creencias, instituciones, técnicas, condiciones geográficas y demográficas.

La civilización latinoamericana es un híbrido entre el mundo occidental y la población americana autóctona. Los procesos independentistas de inicios del siglo XIX se sustentaron de forma decidida en una fuerte construcción nacional y en el culto a los símbolos patrios (bandera, himnos, próceres, etc.), lo cual acentuó las diferencias y singularidades que exteriorizaban cada uno de los nuevos Estados que se erigieron.

Las doctrinas de la retroversión y subrogación fueron factores iniciales que estimularon y/o constriñeron la identidad colectiva regional en el ámbito platense, refiriéndose la 
primera al poder que, al quedar acéfalo, retornaba a la soberanía popular, y la segunda a que el poder hegemónico de la corona española era heredado por la capital virreinal.

Esto nos remite al conocido debate en relaciones internacionales entre agencia y estructura. A grandes rasgos, la tradicional lucha entre los proyectos unitarios y los regionalismos latinoamericanos (la idea confederal). Ambas tensiones aparecen integradas en sus estructuras y son promovidas o rechazadas por diversos agentes. Igualmente, aunque la agencia y la estructura son dos elementos diferentes, desde un enfoque constructivista ambos estarían interrelacionados y construidos recíprocamente.

En apoyo a esta tesis, hemos apelado a una sinopsis de particularidades análogas a la política del Paraguay en la primera República (1811-1870) y Corrientes, para poder constatar cómo los fenómenos de unificación y desmembración son transversales e imprimen su sello, porque transcurren en medio de las políticas expansionistas de las potencias hegemónicas de la región.

El plan confederal de Francia y Artigas venía a satisfacer la aspiración de preservar la unidad del virreinato y a la vez el respeto de la autonomía local, y las condiciones no eran otras que el reconocimiento de las individualidades políticas regionales, la libre navegación de los ríos, el proteccionismo económico y la administración compartida de las rentas de la aduana.

La idea de la integración económica y social como un proceso de complementación en dichos planos, llevado a cabo por diversas unidades políticas institucionalmente iguales y autónomas, que admitiera una sucesión o una yuxtaposición simultánea de grados o formas, con la finalidad de formar un espacio o bloque macroeconómico completo y desarrollado, es un concepto que trasluce la aspiración común de autarquía política y económica, es decir, que el espacio o bloque económico y social se baste a sí mismo, eliminando o atenuando la dependencia política y económica proveniente del feroz y sempiterno rival que se apoya en la pura fuerza bruta justificada en la visión unitaria y elitista de "civilización o barbarie" y el espíritu expansivo del Imperio del Brasil.

Lo anterior revela una notable semejanza en la ausencia de un signo real del Mercosur en sentido de construcción cultural y hace que no dispongamos de su verdadera denotación de equilibrio -acuerdo aduanero, y quizás algo más, entre cuatro-y que debamos resignarnos a manejar sólo una de sus connotaciones: la relativa a aquellos (dos) miembros con mayor territorio, población y número de intereses sectoriales compartidos. Esto último es tan obvio como insuficiente para dar cuenta de la complejidad de este nuevo orden geopolítico americano.

En la visión nominalista, los símbolos -como los que figuran en el Tratado de Asunción de 1991- no son más que meras designaciones singulares y puntuales, apenas válidas para una ocasión coyuntural, en lugar de encarnar tendencias generales, dotadas de consecuencias palpables y empíricas según lo quiere el realismo medieval.

La fuerte y estable relación bilateral entre Brasil y Argentina marca dos pilares de una bilateralidad renovada que continuará funcionando y determinando el devenir de los cuatro países, desarrollada sin considerar la participación del Uruguay y el Paraguay, a los que a la hora de firmar el Tratado de Asunción no se les reconoció siquiera un tratamiento asimétrico en el proceso de integración.

Así el desequilibrio identitario, personal y colectivo, se agudiza cuando se es avasallado por el otro (penetraciones hegemónicas), o cuando se sucumbe voluntariamente a la fusión con el otro y se lo reitera obsesivamente (clonación, la argentinidad de Corrientes), o 
cuando se siente que sin su presencia modélica poco se puede hacer o ser (adición nominal de los países menudos del Mercosur).

La crisis del Mercosur en 1999-2002, como consecuencia de una lejana confrontación dialéctica, pone en riesgo todo el proceso de integración regional por un dilema de identidad, seguido por el cuestionamiento de los proyectos de desarrollo nacional-regional y de inserción internacional, cuyos efectos no contribuyen a solidificar el soporte civilizatorio latinoamericano.

\section{Bibliografía}

ABREU, Sergio (2016). La vieja trenza: la alianza porteño-lusitana en la Cuenca del Plata (1800 -1875). Asunción. Grupo Editorial Atlas.

ANDACHT, Fernando (2001). “Integración/desintegración: nuevos signos de identidad en el Mercosur". Clacso, Buenos Aires, pp $309-340$.

ARPINI, Adriana María (2013), “América Latina / Nuestra América. El quehacer filosófico entre nosotros". Letras 84 (119), pp. $143-172$.

BENEGAS CRISTALDO, Gladys S. (1994) Mercosur a la búsqueda de un mercado común: Creación de comercio, desviación de comercio e implicancias de políticas públicas. Asunción, Universidad Católica "Nuestra Señora de la Asunción".

CABALLERO SANTOS, Sergio (2014). "La identidad en el Mercosur: regionalismo y nacionalismo”. Foro Internacional, México D.F., vol. liv, n 4 , octubre-diciembre, pp. 841-865.

CALDUCH CERVERA, Rafael (2003). “Cultura y civilización en la Sociedad internacional”, en AA.VV. Iglesia, Estado y Sociedad Internacional- Libro homenaje a D. José Giménez y Martínez de Carvajal, Madrid: Edit. Universidad San Pablo-CEU, pp. 299-321.

CASTAGNINO, Leonardo (2010). Guerra del Paraguay: la triple alianza contra los países del Plata. Buenos Aires. Fabro.

CHIARAMONTE, José Carlos (2013). Usos políticos de la historia. 2a - ed. Buenos Aires. Sudamericana.

DOTTA OSTRIA, Mario (2012). Oligarquías, militares y masones: la guerra contra el Paraguay y la consolidación de las asimetrías regionales. 2ª ed. Montevideo. Ediciones de la Plaza.

LAMO de ESPINOSA, Emilio (2018). “¿Es América Latina parte de Occidente?”. Documento de trabajo 18/2018. Madrid. Real Instituto Elcano.

LÓPEZ, Francisco Solano (1996). Proclamas y cartas del Mariscal López. Asunción. El Lector.

MANZONI RUBIO, Luis Benjamín (2005). "Las Instrucciones del año XIII: Artigas como precursor constitucional de la integración económica y social regional". Revista de la Facultad de Derecho, $n^{\circ} 7$, Montevideo, pp. 117-134. Recuperado a partir de https://revista.fder.edu.uy/index.php/rfd/article/view/42. 
MENDOZA MARTíNEZ Hugo R. (2011) “El Paraguay y la Confederación Artiguista”. Armas y Letras, Montevideo, año vii, n 9, pp. $67-84$.

PARADÉS MARTÍN, Marta. "La identidad española y la identidad europea en el apoyo a la Unión Europea", en http://www.fes-sociologia.com/files/congress/11/papers/2337.pdf

RAMÍREZ BRASCHI, Dardo (2018). "Posiciones políticas en la provincia de Corrientes durante la ocupación paraguaya en 1865", en, Ruiz Ortiz, María Paz (Coord.), Memoria del X Encuentro de Historia sobre la Guerra de la Triple Alianza, Asunción: Asociación Cultural Mandu'ará, pp. 69-81.

ROMERO C., Marco (1999). "La comunidad andina: entre la crisis y la falta de identidad (Tema central), en, Ecuador Debate. Integración andina. Quito CAAP, $n^{\circ} 47$, agosto, pp. $65-90$.

TRUJILLO A., Constanza E (2004). "La construcción de la idea europea: la perspectiva histórico-cultural, más allá de la 'identidad'” Desafíos, Bogotá (Colombia), semestre I, octubre, pp 64-93

VERA NORIEGA, José Ángel. \& VALENZUELA, MEDINA, Jesús Ernesto (2012). "El concepto de identidad como recurso para el estudio de transiciones", en Psicología \& Sociedade; 24 (2), pp. $272-282$. 
